\title{
Consumer Attitude and Behavior of Religious Consumers towards Offensive Advertisements
}

\author{
Alina Rashid ${ }^{1}$ and Nasar Khan ${ }^{2}$
}

${ }^{1}$ Department of Clinical Psychology, Beacon House TNS, H 1/2, Street 3, Block H, Khuda Baksh Housing Society, Airport Road, Lahore

${ }^{2}$ Department of Psychiatry, Queens University, 1032 Mona Drive Kingston, Ontario, Canada

${ }^{*}$ Corresponding author: Nasar Khan, Department of Psychiatry, Queens University, 1032 Mona Drive Kingston, Ontario, K7P2P6, Canada, Email: Mnsk@queensu.ca

Rec date: June 24, 2017; Acc date: July 07, 2017; Pub date: July 11, 2017

Citation: Rashid A, Khan N (2017) Consumer Attitude and Behavior of Religious Consumers towards Offensive Advertisements. Ann of Behav Sci, Vol. 3 No.2: 6

\section{Abstract}

The study attempts to investigate the effect of controversial advertisements on consumer attitude, behavior and purchase intention of religious consumers. The study also aims to investigate what difference of attitude is prevailing between men and women. 200 participants ranging in age from 20 to 25 at first were randomly selected. Religious Commitment Inventory - 10 was distributed to the 200 participants. 40 participants (20 males; 20 females) having the highest and nearly equal scores on the $\mathrm{RCl}-10$ were selected. The selected participants were shown censored advertisements first and the responses were collected on Consumer Attitude Questionnaire and Juster's 11 Point Probability Scale. After collecting the questionnaires, participants were shown uncensored versions of the same advertisements, and responses were then collected again on same scales. The analysis of results using t-test and Pearson correlation co-efficient suggested that controversial advertisements negatively affect the consumer attitudes of religious consumers; moreover females with high religiosity are more offended by controversial advertisements as compared to males with high religiosity. However, the analysis of results showed that consumer attitude is not a strong predictor of consumer behavior, as there might be other mediating and moderating variables that shape the ultimate purchase intention and consumer behavior.

Keywords: Consumer attitude; Controversial advertisements; Consumer behavior

\section{Introduction}

In the present day competitive world, success of an industry or organization lays largely upon the effectiveness of it's advertise practice. In order to survive the competition posed by one company over the other, both local as well as multinational companies invest huge sums of money for the advertisement of their products and services. The advertisement serves as a channel to ensure that the consumers are well informed about the products and services being offered by the marketers. However, the offense posed by many advertisement that do not confirm with religion the consumers belong to, must be studied in order to see its effect on other prevailing variables.

Consumer attitude is a comparatively continuing set of beliefs, approach, and behavioral tendency regarding socially considerable objects, events, and symbols [1]. Modudi [2] explains consumer attitude as throwing light upon a person's comparative consistent emotions, evaluation and tendencies headed towards an object or idea. Whereas Consumer buying behavior is the process concerned with when individuals or groups select, acquire or purchase, use the products, service, idea or experience to satisfy desire and needs [3].

Ajzen and Fishbein [4] in their causal chain perspective and in theory of reasoned action (TRA) have defined attitude as a construct where it serves as a function of prominent beliefs rather than just another variable. These theories serve as a premise for predicting behavior from attitude. According to the causal chain perspective, beliefs that a person holds are said to have a causal effect on the attitude of the individual. In other words, the attitude held by an individual is a function of the most salient beliefs held by the individual. Attitude influenced by the most salient believes in turn increases or decreases the probability of a behavior. According to the theory people form intentions to behave only when there is a consistency with the attitude they hold towards something. Intent to purchase is a conclusion which elaborates whether a consumer would purchase a product, service, or concept in particular [5].

In others words, behavior are determined by the intention to behave which is formed by the consistency in attitude influenced by the salient beliefs an individual holds and vis [4]. But here we are interested only in the progressive chain i.e., beliefs form the attitude, which reflect in the intention, which in turn cause the resultant consumer. Controversial advertisement are often said to be such advertisements that leads to a sense of disgust, offense, or negative attitude towards the goods and services in the minds of the consumer [6]. An advertisement becomes controversial either due to the nature of the product, services and concepts being endorsed 
or due to the way an acceptable or uncontroversial product is advertised [6].

A lot of researches in other countries have been done on variables that affect consumer attitude and behavior in order to provide the marketers with definite patterns of consumer response towards non-conformity advertisements. However a few studies that have been done in Pakistan and even they do not define the variables in detail. Regardless of the evidence that religious conviction affects social behavior, there is less literature available to this present date regarding the religious influence (Islamic perspective) swaying over attitude and behavior of potential religious consumers [7]. This study aims to explore the association between religious conviction and consumer attitude and how consumer attitude in turn influence purchase intension. This study aims to investigate, how the religious perceptions of religious consumers affects their attitude towards the controversial advertisements and consequently towards products as well. Aiming to outreach, the study would be an approach in helping marketers comprehend specifically the response pattern towards controversial advertisement and product as shaped by the religious perceptions of the consumer. In addition, it aims to help marketers find the relationship between attitude and buying behavior of the religious consumers by controlling the associated variables. Since the rapidly changing trends mean that the current literature related to this topic is limited in Pakistan, it calls for an improved research in this field to enhance our understanding with respect to controversial advertisements and consumer attitudes of religious people.

\section{Objectives}

- To investigate the effect of offensiveness of an advertisement on consumer attitude of religious consumers.

- To find out the relationship between consumer attitude and purchase intention.

- To find out the difference in consumer attitude of males and females towards controversial advertisement.

\section{Hypotheses}

H1: Controversial advertisements negatively affect the consumer attitudes of religious people towards the product.

H2: There is a significant relationship between consumer attitude and purchase intention.

H3: Females with high religiosity are more offended by controversial advertisements as compared to males with high religiosity.

\section{Experimental Design}

Experimental design was used for the study and variables included offensiveness of advertisement (independent variable), consumer attitude, purchase intention, consumer behavior (Dependent variables) and; religious intensity of consumer, age, and gender (controlled variables).

\section{Sample}

A sample of 200 university students (100 males and 100 females) from three universities of provincial capital of Pakistan was selected ranging in age from 20 to 25 . The Religious Commitment Inventory-10 ( $\mathrm{RCl}-10)$ was administered on the sample in order to find people with nearly same high scores. The rationale for selecting such a big sample before sorting into experimental group is that the larger the sample, the greater is the probability of finding participants for experiment group with identical scores on The Religious Inventory-10. Based upon the scores of $\mathrm{RCl}-10,40$ people (20 males; 20 females) were selected with the similar scores. This procedure helped to reduce sample bias.

\section{Procedure}

The research was divided into two stages.

\section{Stage I}

The first stage tries to find out whether the offensive advertisements cause an unfavorable attitude among religious consumers, whereas the second stage comprises of finding the relationship among consumer attitude, purchase intention, and consumer behavior of the religious consumers. To find the relationship between controversial advertisements and consumer attitude, the repeated measure design required formulation of an experimental group. The group comprised of 40 participants i.e., 20 males and 20 females. The participants in experimental group were similar to each other in terms of religious perspectives because of the purpose sampling technique used in the underlying study. Purposive sampling ensured that participants in the experimental group have near to or similar scores on $\mathrm{RCl}-10$.

\section{Stage II}

Individuals were assigned to experimental group and consent and demographic form were distributed to them. After getting the consent and demographic forms filled, advertisements of four already selected products/brands were shown to the participants. The four brands and products are i.e., (a) perfumes by Gucci, (b) Clothing by Dolces and Gabbana, (c) Ice cream by Federici and (d) Perfume by Just Cavalli. The experimental group was shown censored ads first. After showing them the censored advertisements, participants were given questionnaire of consumer attitude and purchase intention to fill. After getting the questionnaire filled, participants of experimental group were shown uncensored version of the same advertisements and the same questionnaire were distributed again to see any disparity may arise after watching the uncensored advertisements. The survey questionnaire comprised of questions that measure consumer attitude and purchase intention. 


\section{Results}

The results showed, attitude of religious consumers is higher when they were shown censored advertisement as compared to the attitude of the same religious consumers when they were shown the controversial and uncensored advertisement of the same products (Table 1).

Table 1 Mean standard deviation, paired sample t-test and $p$ value of pre and post-consumer attitude of religious consumers.

\begin{tabular}{|l|l|l|l|l|}
\hline Variables & $\mathbf{M}$ & SD & $\mathbf{t}$ & $\mathbf{p}$ \\
\hline Pre Attitude & 16.63 & 2.789 & 14.113 & .000 \\
\hline Post Attitude & 9.28 & 2.846 & & \\
\hline Note: ${ }^{p} p<0.05$ & & & \\
\hline
\end{tabular}

Moreover, the results depict that there is a significant difference in pre (censored advertisement) and post (uncensored controversial advertisements) consumer attitude of religious consumers. The mean of pre consumer attitude in response to the censored advertisement $(M=16.63)$ is greater than mean of post-consumer attitude in response to uncensored advertisement ( $M=9.85)$. Based on the results, it can be said that controversial advertisements negatively affect the consumer attitudes of religious people towards the product.

The results further depicted (Tables 2 and 3), there is no significant relationship between attitude of religious consumers towards controversial advertisement and their purchase intention.

Table 2 Pearson product moment correlation coefficient among pre attitude and pre purchase intention of religious consumers $(\mathrm{N}=40)$.

\begin{tabular}{|l|l|l|}
\hline Variables & $\mathbf{r}$ & $\mathbf{p}$ \\
\hline Pre Attitude & 0.284 & 0.76 \\
\hline Pre Purchase Intention & & \\
\hline Note: $p=n . s$ & \\
\hline
\end{tabular}

Table 3 Pearson product moment correlation coefficient among post attitude and post purchase intention of religious consumers $(\mathrm{N}=40)$.

\begin{tabular}{|l|l|l|}
\hline Variables & $\mathbf{r}$ & $\mathbf{p}$ \\
\hline Pre Attitude & & \\
\hline Pre Purchase Intention & 0.83 & 0.611 \\
\hline Note: $p=$ n.s & \\
\hline
\end{tabular}

Moreover, the mean of males' consumer attitude towards controversial and uncensored advertisement $(M=10.40)$ was higher than the mean of females' consumer attitude ( $M=$ 8.15).

This shows that females with high religiosity were more offended by the controversial (uncensored) advertisements as compared to males with high religiosity.

\section{Discussion}

The result of the experiment suggested that attitude of religious consumers is higher when they were shown censored version of the controversial advertisements $(M=16.63)$ when contrasted with the customer attitude of the same religious consumers when they were demonstrated the disputable and uncensored commercial of the same items ( $M=9.28)$. Additionally, the outcomes portray that there is a critical distinction in pre (censored commercials) and post (uncensored disputable commercials) consumer attitudes of religious consumers. As Waller says, "religiosity is an important variable to be considered while examining society's attitude towards controversial advertisement." Akhtar [7] deems to agree with the findings of Waller [8,9] by surveying 200 university students at COMSATS Institute of Pakistan. The results as obtained by the study showed that respondents were offended by the controversial and offensive advertisements. Moreover, it was found that respondent perceived indecent language as the least offensive advertisement appeal whereas the post offensive advertising appeal came out to be the sexist images. In similar lines with Akhtar [7], Waller [8] suggests that male and female both sex show unfavorable consumer attitude towards the controversial or offensive advertisements. However, they both deem to be differing in their religious perceptions as females tend to be more offended as compared to males.

The results suggested that the stance or attitude of religious consumers regarding advertises of the products and services do not unswervingly predict or contribute to purchase intention. People with high religiosity generally had negative attitude toward the uncensored controversial advertisement $(M=9.85)$. However, the purchase intention of the religious consumers towards controversial advertisement and the respective products does not seem to have a significant relationship with the attitude that those religious consumers hold. This suggests that consumer attitude is not predictive of consumer behavior. The suggested results, of course, are not intelligible with the literature that negative attitude regarding the advertisement can prompt positive or impartial consumer behavior.

Normally, behavior of the consumers keep up a correspondence with the attitudes they hold [10], however it is not impossible to both say and assume that there seems to 
be inconsistency between consumer attitude and consumer behavior. Putting it the easy way, it is possible to assume that consumers might hold negative consumer attitude towards the products or services being endorsed in the controversial advertisement but still have a partial or positive purchase intention. Previously it has been demonstrated through scientific evidence that consumer attitude do dependably foresee individuals' behavior or intention to behave [11]. A conceivable reason to explain the inconsistency between attitude and behavior is the vicinity of different elements which were not a part of the investigation, which moderate or mediate the relationship between attitude toward the advertisements and purchase intention.

The experiment, in regard to the research objective established the mechanism of attitude - behavior inconsistency. Attitude cannot anticipate the consumer behavior, as moderating and mediating factors may be present to modify the absolute consumer behavior. Putting it in simpler words, it is to say that for attitude - behavior inconsistency; different factors are available to make the assumption logical. Moreover, the hasty globalization and escalation of media channels supported by satellite in greater part of the Islamic world resulted in recurrent unrestricted encountering of advertises of offensive products. List of controversial advertisements that our media put up can be ongoing if they are to be listed. These advertisements have instilled in the consumers a sense of acceptance although their attitude might differ. The likelihood for such recurrent encounters generates having developed a certain lenience or tolerability of such services or controversial products in the Islamic society.

\section{Conclusion}

The study indicates the religiosity of an individual is an important predictor of his consumer attitude and consumer behavior towards various products, services and concepts the marketers offer through advertisements. The controversy in the advertisements sensitizes the religious believers and instills in them a sense of offense regarding either the particular advertisement or the respective products. Moreover, people will high religiosity are assumed to have affiliations with other cults of people with same religious believes hence it is imperative to say that the consumer attitude of one religious consumer can affect or influence the consumer attitude and behavior of other religious consumers.
The history is not short of examples where strong negative consumer attitude of one religious consumer had mobilized millions of other religious believers to cast out the hatred in non-conventional ways. The study suggests that consumers with high religiosity are more offended to controversial advertisements as compared to when the advertisements are not controversial or offensive to their religious believes in nature. The marketers need to understand the psyche of the religious consumers and plan to advertise in a way that does not offend any religious segment. Furthermore, females with high religiosity are more offended by advertisements controversial to their religious believes as compared to males with high religiosity. However, as indicated by the study, consumer attitude of religious consumers does not indicate consumer behavior.

\section{References}

1. Hogg M, Vaughan G (2005) Social psychology. Prentice-Hall, London, UK.

2. Modudi A (2003) Islamiriasat. Islamic Publications Pvt. Ltd., Lahore, Pakistan.

3. Solomon M, Bamossy G, Askegaard, S, Hogg M (1999) Consumer behavior: European perspective. Prentice Hall, England, UK.

4. Fishbien, M, Ajzen I (1975) Beliefs, attitudes, intentions and behavior: An introduction to theory and research. Adison Wesley Publishers, Pearson Inc., Massachusetts, USA.

5. Porter ME (1974) Consumer behavior, retailer power and market performance in consumer goods industries. The Review of Economics and Statistics p. 419.

6. Barnes JH, Dotson MJ (1990) An exploratory investigation into the nature of offensive television advertising. J Advertising 19: 61-69.

7. Akhtar W, Abbasi AS, Umar S (2011) Ethical issues in advertising in Pakistan: An Islamic perspective. World Appl Sci J 13: 444-452.

8. Waller DS (1999) Attitudes towards offensive advertising: An Australian study. J Cons Mark 16: 288-294.

9. Waller DS (2000) Cultural values and advertising in Malaysia, Asia pacific. J Mark and Logis 12: 3-16.

10. Schiffman G, Kanuk L, Leslie L (2004) Consumer behavior (8th edn), Pearson, Prentice Hall, New York, USA.

11. Kraus SJ (1995) Attitudes and the prediction of behavior: A meta-analysis of the empirical literature. Pers Soc Psychol Bull 21: 58-75. 